\title{
The Impact of Blockchain on the Accounting Profession
}

\author{
PhD. Elena Alina OLARU (COLBEA)
}

"Ştefan cel Mare" University of Suceava, Romania

\begin{abstract}
The implementation of the blockchain technology in accounting highlights the automation of traditional accounting functions and the transparency, significantly mitigates the risk of internal fraud and increases the importance of the financial information provided and the trust in that information. Professional accountants need to prepare to accept digitalisation as a challenge to become more experienced and to consolidate their status as a reliable third party. In this article we present the blockchain technology and its probable impact on the accounting profession. The aim of this study is to analyse the research on information technologies in accounting and the way these technologies could modify the industries and professions in time.
\end{abstract}

Key terms: accounting, blockchain, information technologies, audit

JEL Classification: M41, M49, O33

To cite this article: Elena Alina Olaru (Colbea), The Impact of Blockchain on the Accounting Profession, CECCAR Business Review, N 4/2021, pp. 63-72, DOI: http://dx.doi.org/10.37945/cbr.2021.04.08

\section{Introduction}

Computer technologies occupy an increasingly important place in our daily lives. They are ubiquitous not only for younger generations who live in their computers. Information technologies are no longer just tools, having become an integral part of their lives. Social networks have become an integral part of the younger generation's routine and represent the permanent connection with their "friends". The young population sees SMS as old-fashioned and communicates using a variety of permanent communication methods: dozens and sometimes even hundreds of messages a day. Technology has thus become a tool of vital necessity - we are no longer able to live without it.

The approaches of different specialists prompts the importance of analysing the impact of blockchain on the accounting profession. The aim of this work is to better emphasize the main aspects resulting from the use of blockchain technology in a wide range of industries, including accounting. Thus, this qualitative research provides notions of the advantages and disadvantages of integrating blockchain technology into the accounting profession. The result of the research may be a starting point for the further development of the accounting profession.

\section{O Research methodology}

The research methodology consists of the analysis of challenges encountered in the implementation of blockchain technology in the accounting profession. The research methods used are qualitative analysis by documenting, observing and interpreting the procedures used. As international and national regulations in this area are in a process of permanent change, accounting professionals need to reposition themselves as experts in order to be able to respond to evolving challenges and support new business models. 
The main objectives are to:

- research literature on the impact of blockchain on the accounting profession;

- analyse implications of professional judgment by examining the advantages and disadvantages of using blockchain technology in accounting;

- submit conclusions.

The main research questions are related to the objectives of the research:

$\checkmark$ What are the advantages and disadvantages of implementing blockchain technology in the accounting profession?

$\checkmark$ Will blockchain revolutionize the accounting profession?

\section{Presentation of blockchain technology and impact analysis on the accounting profession}

The disruptions caused by COVID-19 reinforce the significant contributions of the accounting profession to every player in the economy worldwide. During this period, the challenge of accounting professionals was to accept digital transformation in order to meet the new, unique needs of firms and organisations. Commercial activities are transformed; they now aim for a highly simplified, accessible and available manner. Bertrand Duperrin, one of the most important digital specialists in France, gives us the following definition of digital transformation: "achieving simple, pleasant, engaging and efficient things for the customer and employee at every point of contact" (Stiller et al., 2011).

Thus, blockchain appears as a new abstract approach that needs to be put into practice, targeting all levels of innovation. Peter Drucker (2008) said: “The greatest danger in times of turbulence is not turbulence - it's to act with yesterday's logic.".

For the first time, to solve mistrust between business partners, Stuart Haber and W. Scott Stornetta developed a project of the cryptographic secure blockchain, known today as blockchain technology. After the 2008 economic crisis, this project was developed as a solution for securing financial transactions made through various institutions, organisations and economic entities. Thus, the misconception emerged that blockchain is a single technology because the original blockchain was created to record transactions with the virtual currency Bitcoin.

The research of literature shows that blockchain is considered the "uberization of uberizeres" in that it is capable of revolutionising several sectors of economy and society. Blockchain is a storage and information exchange technology that works transparently and securely without a main control body.

The Bank of England, the UK's central bank, describes blockchain as a "technology that allows people who don't know each other to trust a shared record of events" (https://bankunderground.co.uk/2019/05/16/buildingblocks-the-useful-elements-of-blockchain/). In other words, blockchain can, in theory, allow partners to manage without a traditional trusted third party, which removes intermediaries and therefore infrastructure charges. France defines it as "a shared system of electronic record-keeping" (https://www.banque-france.fr/sites/default/ files/medias/documents/words-in_the-news_blockchain.pdf).

The peculiarity of this technology is that any transaction registered in a block, whose authenticity is attested not by a trusted third party, such as a bank, but by a global community of user members who solve math problems using powerful computers. When the block has been validated, it is recorded in the long chain made up of all the blocks from the beginning. The register is considered impossible to defraud because the computing power required for change seems impossible to obtain. This would require several thousand copies of the forged register at the same time. 
Blockchain technology thus becomes a special type of decentralized public record. It is a public ledger, without localization on a central server and is not subject to the monopoly of administration or control. Transactions on blockchain platforms are unmediated, with participants acting as peer-to-peer (P2P). A transaction once undertaken can no longer be retroactively modified (block) and is recorded in a chain in a continuously developing database that maintains the "chains" of transactions (chain).

Sharing and storing this accounting register on the network, making it available to users and ensuring its decentralised storage, is a good way to prevent registration misconduct and fraud. Data and transactions are considered to be more truthful if they are distributed throughout the community, as a person or group of persons cannot have a monopoly or control over the information collected and stored. Unlimited access to information is control, i.e. uncertainty and loss of data neutrality, while decentralisation is equity and equitable division of cognitive work.

Blockchain is one of the technologies that guarantees confidence in next-generation systems because it is based on the idea of processing all types of transactions without an intermediary. Intermediaries, such as corporations and governments, are almost always central entities that receive, process and store transactions. All the trust we place as users in any mechanism is trust in intermediaries who are required to process transactions using the correct business logic. Intermediaries fully control the security of information and its confidentiality. In the case of blockchain technology, trust is decentralized. Users just need to trust the mechanism and the smart code that is shared among all participants.

Technically, blockchain is a distributed database that exists on a P2P network (Figure 1). This P2P network represents the backbone of the mechanism because each node in the system is at the same level as all other nodes. Although nodes can have multiple shapes, there is no central node that has control and authority. Each node stores a local copy of the blockchain. If the node agreement agrees to the validation of the transaction, then the transaction is considered valid.

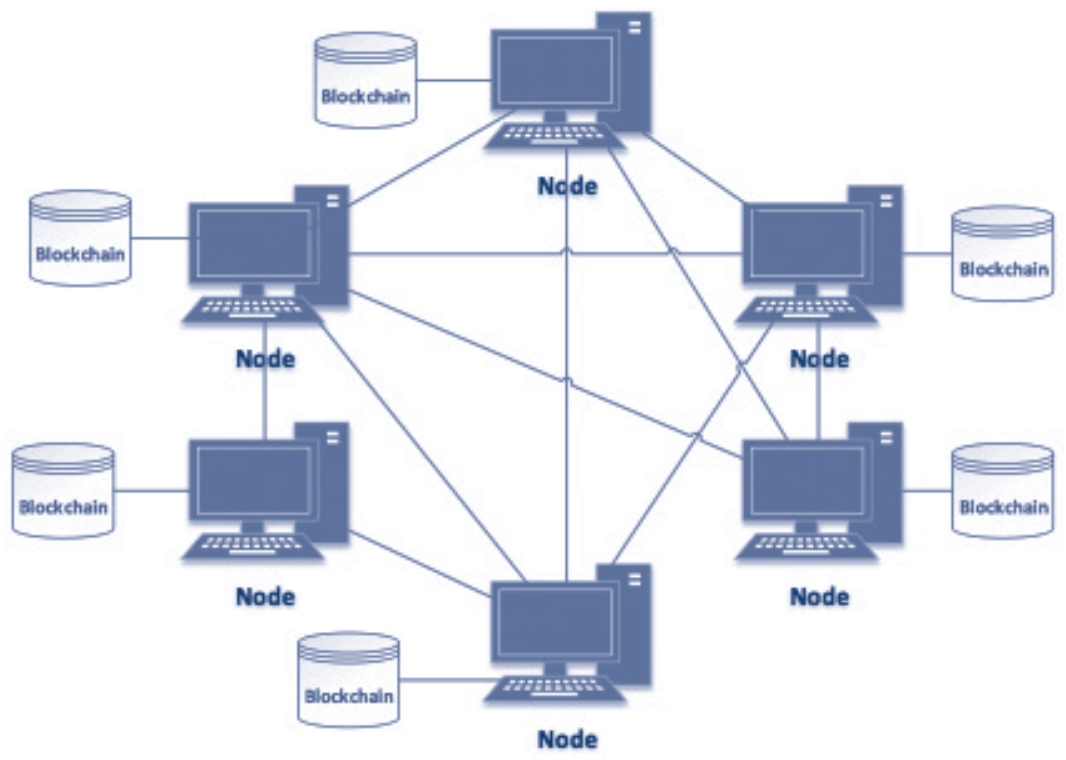

Figure 1. P2P blockchain network

Source: https://seydinabayendanediouf.medium.com/blockchain-a-technical-introduction-part-2-6f75e2a49b89

The blockchain database can be a simple registry that stores only the minimum necessary data about encrypted transactions. All transactions are grouped into blocks marked with a date (time) (Figure 2). 


\begin{tabular}{|c|c|c|c|c|}
\hline Block N & & Block 3 & Block 2 & Block 1 \\
\hline Header data & & Header data & Header data & Header data \\
\hline Transaction 1 & & Transaction 1 & Transaction 1 & Transaction 1 \\
\hline Transaction 2 & & Transaction 2 & Transaction 2 & Transaction 2 \\
\hline Transaction 3 & $\cdots$ & Transaction 3 & Transaction 3 & Transaction 3 \\
\hline 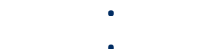 & & e & • & $\cdot$ \\
\hline . & & . & . & . \\
\hline Transaction $\mathrm{N}$ & & Transaction $\mathbf{N}$ & Transaction $\mathbf{N}$ & Transaction N \\
\hline
\end{tabular}

Figure 2. Blocks of blockchain

Source: Author's contribution.

Once a transaction is blocked, it becomes irreversible. All nodes can have access to transactions, but cannot distort or delete a transaction from the blockchain. The logic of the exchanges through which nodes operate is defined in so-called smart contracts. These specify the rules to be followed before a transaction is executed. They are grouped as scheduled rules for writing and reading in the blockchain database. Smart contracts are installed and can be found on each node.

Blockchains can be public and private. For example, Bitcoin is a public blockchain because it was built to be completely open, decentralized and without access permissions. Thus, anyone can intervene without establishing an identity and there is no central authority to control access.

Building on this principle, other blockchain-like platforms have emerged, such as Hyperledger (https:// www.hyperledger.org/news/announcements). It addresses a new interpretation of the blockchain model, partly by managing the acceptance and control of participants. In other words, Hyperledger is a permitted shared register, adjusted to meet a variety of cases and industrial usage requirements in the form of a secure model for identity. In this case, the new techniques replace the requirement of mining blocks, because the environment is more controlled and consists of a smaller number of nodes that are approved, so that exploitation can be avoided and consensus becomes simpler due to the rules used.

Through the research of literature we noted that most studies have focused on one or more particular directions related to the implementation of blockchain. As far as we can see, the quality requirements and solutions for blockchain implementations have not been thoroughly researched. This type of research can help identify quality requirements that can be considered in new blockchain deployments. In addition, this type of research will help us understand how different blockchain features and current problems could positively influence the quality of blockchain systems.

\section{Involvement of professional judgment in terms of analysis of the advantages and disadvantages of using blockchain technology in accounting}

User confidence in blockchain technology is guaranteed by high data integrity, security, reliability and privacy of the node (Porru et al., 2017).

Digitalisation, as a stage of industrial revolution, represents the opportunity for accountants to transform their profession. This turning point began with the restructuring of documents used by switching from the cumulative documents to the use of spreadsheets, and currently not only the way of working is evolving but also the role of the accountant itself.

In the development of blockchain, three generations have been identified, according to Figure 3 : 


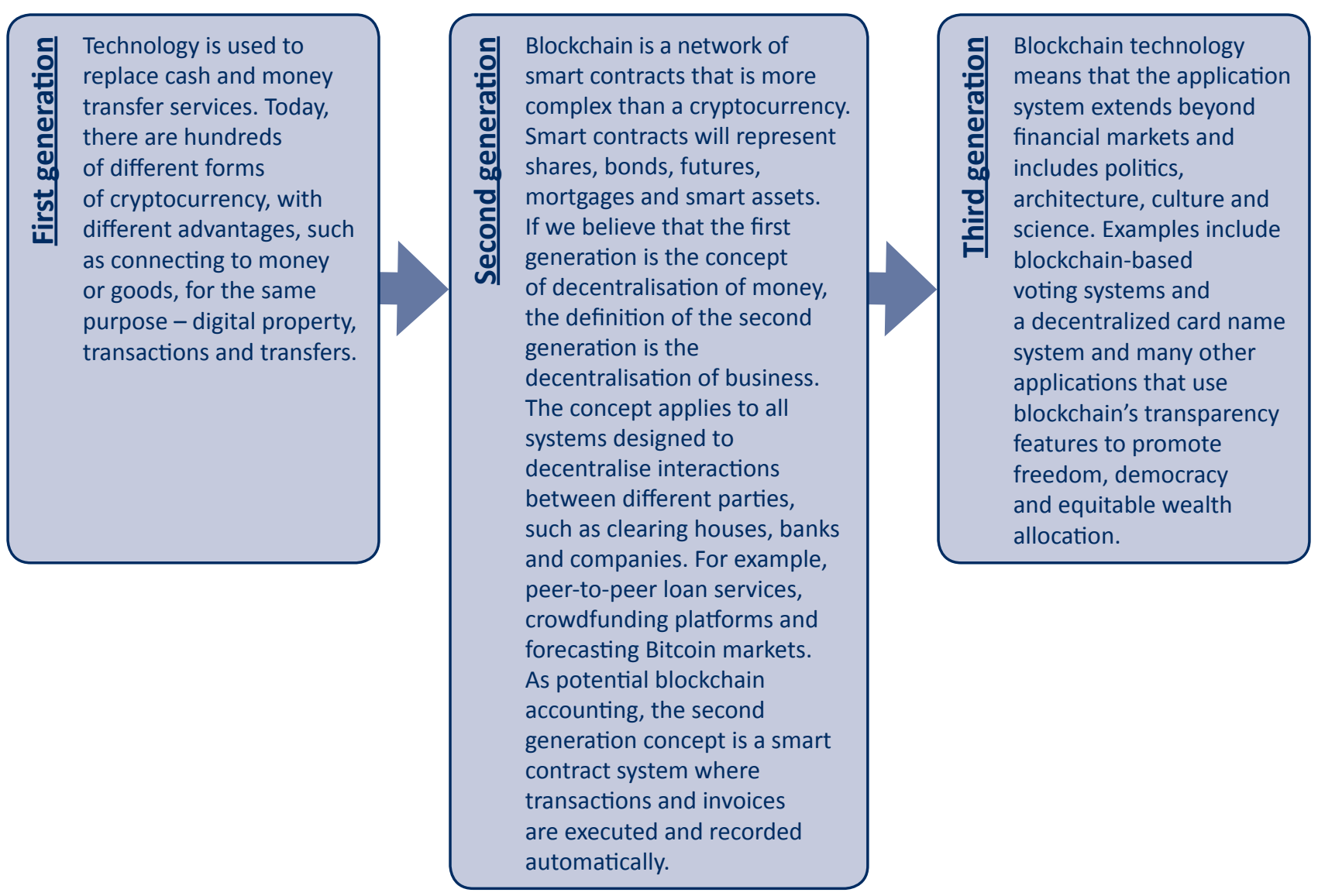

Figure 3. Stages in blockchain development

Source: Potekhina \& Riumkin, 2017, pp. 10-11.

Blockchain has become an international technology that manages to effectively link the financial world and deliver conclusive benefits by reducing risk and enabling efficient allocation of resources (Potekhina \& Riumkin, 2017).

In December 2015, the U.S. Nasdaq exchange confirmed that issuers were able to conduct financial transactions through its blockchain network. The Sydney Stock Exchange's first blockchain prototype was launched in May 2016, which is "the first step towards a fast trading platform for settlement and trading transfer" (Wang \& Kogan, 2017), as confirmed by Potekhina and Riumkin (2017). Blockchain technology and its many forms of implementation are becoming a key factor for innovative ideas and solutions in the financial sector. However, the theoretical framework of blockchain technology, even for the financial industry, is still viewed with disbelief due to insufficient knowledge.

Since accounting cannot be separated from the economic relations system in an economy, as well as from the technical and economic achievements of the present (Hussein et al., 2006), blockchain technology provides the technical infrastructure which, together with accounting terminology, may be the starting point for changes in the methodological regulations of audit and accounting activities (Shyshkova, 2018). This means that accounting should be oriented in order to develop its methods and procedures in accordance with the modern technology environment. The next step will be the requirement to rethink the issuance of the accounting and audit standards necessary to guide accountants and auditors in their profession. 
Blockchain has emerged at the same time as cryptocurrencies and smart contracts as an alternative to computing records. Given the possible of applications in accounting technology, professionals in the field have expressed the expectation that blockchain will mark the future of the accounting record.

Studies of this IT technology have highlighted several areas where blockchain has helped and supported accounting and auditing. These areas include:

- blockchain from an accounting perspective:

- use of blockchain in the design of accounting information systems;

- increasing the efficiency of accounting information systems;

- increasing the importance of managerial accounting;

- blockchain from an audit perspective: blockchain's emergence creates new opportunities and challenges for continuous auditing and real-time accounting. Continuous auditing and real-time accounting are built by developing integrated and real-time accounting information systems to create more accessible and even cheaper activities. Moreover, the stability and rebound feature will facilitate the exchange of information and the prevention of fraud.

Although the blockchain accounting and auditing app is still in its infancy, it will be encouraging to witness the sharing of financial statements with high-level security and privacy (Wang \& Kogan, 2017).

Blockchain technology is new and has not yet reached widespread use. However, in its past uses, the foundations were laid for the creation of premises for the development of information technology and its entry into the modern business environment based on information technology. Thus one may notice some potential effects on the use of blockchain in accounting information systems, based on the use of electronic means:

- impact on accounting activity;

- influence on the design of accounting information systems;

- possibility of reducing the costs of protecting the integrity of information and increasing the rate of transactions settled;

- impact on the transparency of management decisions;

- challenges of applying blockchain technology in accounting.

As regards the impact on the accounting profession, it should be noted that the transition to a financial system based on blockchain technology will provide a number of incentives for the accounting profession. Because it is a new approach, accounting professionals have the opportunity to lead and influence how blockchain is to be implemented and used in the future. To truly become an integral part of the financial system, blockchain needs to be developed, standardized and strengthened. This process certainly won't happen overnight - it's been more than 12 years since Bitcoin started working and there's still a lot of work left. There are also many blockchain implementations and project testing, but there are very few concretes.

Accounting professionals are already interested in research because most have the discipline to do so. Setting up rules and standards for blockchain reporting will be a big challenge, and leading accounting firms should offer their skills in this activity. Accountants can also serve as business guides, given the major need to assess the costs and benefits of the new system. The expertise of accountants in business and finance transforms them into important advisors for entrepreneurs looking for new opportunities for expansion by implementing these new technologies.

Regarding the influence of accounting information systems, Deloitte (2016b) notes that blockchain technology is a reliable, distributed, open system available with minimal usage costs. Using blockchain for accounting purposes is a new challenge for the accounting profession as it may facilitate compliance with regulatory requirements in order to improve the current accounting system. 
Blockchain often refers to various payment systems or even specific accounting standards (e.g. GAAP and IFRS). In order to achieve impartiality, it is important to distinguish the documentation of accounting activities. Blockchain technology functions as a shared, neutral database that holds the transaction records. The system also allows managers and auditors to compile individual transactions and produce financial reports at their own discretion (Wang \& Kogan, 2017).

In the use of blockchain technology, real-time accounting procedures are a software solution that allows currency transfers, derivatives and other electronic transfers between two or more entities and stores transaction data in encrypted blocks. Their credibility shall be verified and the financial statements may be drawn up at any time.

To add value to businesses and their shareholders, it is important that the blockchain accounting system has the following real-time features:

- transparency - transactions should be available in real time, as in the case of Bitcoin;

- stability - no programming capacity should be granted to modify transaction elements;

- accessibility - data must be available to a wide range of users.

As regards the reduction of the costs of protecting information, blockchain technology can be integrated into accounting procedures. The essential characteristics are as follows:

- high degree of use - maintaining the accuracy of information for fully monitorable audit reports and fully automated audits can become a reality;

- continuous - for each customer that has their own version of the register, the reality is universally agreed, previous transactions cannot be changed without majority approval, which ensures that the information recorded by blockchain technology is irreversible, the entire register is kept by all parties and can be verified and confirmed in real time;

- programmability - some strings used by blockchain allow to store ledger entries and create journal entries that are executed automatically under the name of smart contracts.

In terms of transparency of decisions, businesses using blockchain are considered more transparent, as blockchain enables the identification of a database that can be tracked and allows the creation of a full-time framework for all decisions and actions taken by management. BoardRoom is a pioneering example of blockchain software governance created by Ethereum. For future applications, users will be able, for example, to electronically register votes on user recommendations on blockchain (CPA Canada, 2016). Financial reports made and published in a timely manner, both quarterly and annually, are relevant to a wide range of investors and the financial market as a whole, as they are considered to provide the most significant source of data on the financial health of enterprises and their future prospects. Most research shows that shareholders' reaction to late reporting of financial statements is negative and that delays are often perceived as a sign of accounting or management problems, and may also mean that management is trying to manipulate data (Potekhina \& Riumkin, 2017).

With regard to the application of blockchain in the field of accounting, it is not only the advantages of using blockchain technology in accounting information systems, but also the obstacles that may arise.

Coyne and McMickle (2017) identified three of the constraints or obstacles that could make it difficult to apply blockchain to accounting:

- data privacy - the desire for data confidentiality is justified because lists of suppliers and customers, unit costs and tactical transactions held in the register can become profitable trade secrets;

- the ability of companies to deal retroactively with their own blockchain; 
- a blockchain's limited ability to verify transactions - even if the customer and vendor share the responsibility to validate the transaction in such a way that they do not have high rewriting capacity, transaction validation will remain unsuccessful for the accounting officer if operating errors occur.

Other obstacles that could hinder the deployment of blockchain technologies refer to the fact that blockchain authentication techniques are not adequate to verify payment from an accounting point of view because blockchain technologies do not know how to recognise the reality and peculiarities of transactions. Accounting professionals know that checks are still needed to prevent fraud and deal with errors, and implementing blockchain will not help eliminate this. For example, blockchain will not prevent the diversion of goods, nor will it prevent the incorrect calculation or estimation of legitimate transactions.

By analysing the advantages and disadvantages of blockchain technology in different fields of activity, we will certainly see implementations especially in the control system and automatic checks that are already integrated into the enterprise resource planning software (ERP). Thus, controlling processes in ERP involve the same effort as migrating information into a smart blockchain contract. So, unless some processes start becoming easier, accounting professionals don't envision a big shift from ERP to blockchain technology.

The technology will certainly mature, and the accounting profession and society will become more comfortable with smart contracts and blockchain technology because artificial intelligence can help us automate some accounting functions. But in order to improve them, artificial intelligence needs a large set of data.

Already this technology is transforming the supply chain: we know in real time the quantities that pass through every stopping point in the chain, when they pass through every point, when they reach the shops. Non-financial information can be entered into the accounting system to be used subsequently in accounting processes, such as three-way matching, validations on purchase orders or validations on invoices or write-offs, which could occur, for example, if frozen foodstuffs have to be written off because the temperature has risen too much either in storage or during transport.

It is natural to look at blockchain technology in the context of automation, but without losing sight of convergence with other technologies, because blockchain is not the only technology that will lead to automation. We need to have data from devices that are on the Internet of Things (IOT), so we will have a variety of loT devices that will be able to work with blockchain to provide this data. The emergence of things like the $5 \mathrm{G}$ cellular will allow us to have more devices online and faster connectivity for these devices. So those devices on the Internet of Things, associated with $5 \mathrm{G}$ speed and capacity, and characteristics like blockchain immutability will provide artificial intelligence with all this information which will provide us with additional data to help the accounting professional of the future really become more than business advisors and consultants to their clients.

\section{P Conclusions}

In this study we analyzed the most important implications of implementing blockchain technology in accounting information systems by adjusting the accounting practices appropriately. Blockchain technology is one of the most recent developments in the information technology environment, used in financial markets, because it was the basic technique for trading the Bitcoin currency and then expanded its use to include the world of commerce.

The advantage of using blockchain technology is that there is no intermediary (third party) for transactions taking place between two parties, as well as the lack of a central owner that controls it. Due to the close relationship between accounting and the world of finance (in financial markets) accounting confidence has been affected by financial transactions between parties. Thus, by using blockchain technology in the accounting activity of many companies, the aim was to regain confidence in the accuracy of the reported financial statements (especially those of US companies registered in financial markets). 
The use of blockchain technology in accounting in particular requires the development of accounting information systems to have an impact on terms and components, with the need for a complete transition in the design of accounting information systems to sophisticated and technically advanced digital programs and applications.

On the basis of the above-mentioned, we underline the importance of providing accounting professionals with the necessary technology and knowledge to work in the modern technology environment, in particular with regard to blockchain technology and its current and potential accounting uses in the context of rapid and successive developments in the information technology environment.

Scientific research in identifying the areas of use of blockchain technology in accounting and auditing activities is initially in this area by theorizing and applying research results in this environment (as companies or as financial markets).

Academic and professional associations specialising in accounting and auditing should also consider the possibility of initiating accounting projects and audit standards that can guide accountants and subsequent auditors to catch up with the latest developments in the information technology environment. It is therefore necessary to think about how to prepare future accounting professionals, but also to update the accounting and audit standards that will guide accounting professionals and auditors, as well as internal auditors.

The limitations of this study are the impossibility of conducting an empirical test or a case study or a survey using real data. However, it opens up many opportunities for researchers to conduct future debates addressing these limitations by using applied and experimental tools to test the importance of determinants and requirements of blockchain technology in accounting or auditing.

\section{References}

1. Abdulsahib, G.M., Khalaf, O.I. (2018), Comparison and Evaluation of Cloud Processing Models in Cloud-Based Networks, International Journal of Simulation: Systems, Science \& Technology, Vol. 19, No. 5.

2. Ali, S., Mahmood, S.M., Hussein, A.I., Hussein, S.S. (2018), The Impact of IFRS Adoption on the Relationship Between Corporate Governance and Agency Costs, Opción, Vol. 34, No. 86, pp. 2279-2297.

3. Coyne, J.G., McMickle, P.L. (2017), Can Blockchains Serve an Accounting Purpose?, Journal of Emerging Technologies in Accounting, Vol. 14, No. 2, pp. 101-111.

4. Cudahy, G. (2016), Blockchain Reaction: Tech Plans for Critical Mass, https://www.ey.com/Publication/ vwLUAssets/ey-blockchain-reaction-tech-companiesplan-for-critical-mass/\$FILE/ey-blockchain-reaction.pdf.

5. Drucker, P.F. (2008), Managing Oneself, Harvard Business Review Classics.

6. Hussein, A.I., Mahmood, S.M., Hussein, W.N. (2018), The Relationship Between the Accounting Conservatism and the Financial Performance Efficiency of the Banks According the Data Envelopment Analysis: Evidence from Iraq, Opción, Vol. 34, No. 85, pp. 2661-2686.

7. Hussein, S.S., Mahmood, S.M., Hussein, A.I. (2006), The Effect of the Electronic Commerce on Accounting Information High Quality, Tikrit Journal of Administrative and Economic Sciences, Vol. 2, No. 3, pp. 130-151.

8. Ismail, S.A., Mahmood, S.M., Hussein, A.I. (2019), The Impact of the Agency Costs on the Going Concern Under the Auditor Industry Specialization: An Empirical Study on Private Banks in Iraq, Aus, Vol. 26, No. 3, pp. 55-63.

9. Khalaf, O.I., Sabbar, B.M. (2019), An Overview on Wireless Sensor Networks and Finding Optimal Location of Nodes, Periodicals of Engineering and Natural Sciences, Vol. 7, No. 3, pp. 1096-1101. 
10. Orcutt, M. (2018), How Secure Is Blockchain Really?, MIT Technology Review, Vol. 121, No. 3, pp. 18-23.

11. Porru, S., Pinna, A., Marchesi, M., Tonelli, R. (2017), Blockchain-Oriented Software Engineering: Challenges and New Directions, în IEEE/ACM 39th International Conference on Software Engineering - Companion, pp. 169-171.

12. Potekhina, A., Riumkin, I. (2017), Blockchain - A New Accounting Paradigm. Implications for Credit Risk Management, Master degree thesis, Umeå School of Business and Economics.

13. Rakhmawati, N.A., Hanindito, D. (2018), An Integrated Assessment System of Citizen Reaction Towards Local Government Social Media Accounts, Journal of Information Technology Management, Vol. 10, No. 3, pp. 1-19.

14. Rückeshäuser, N. (2017), Distributed Ledgers for the Prevention of Accounting Fraud. Blockchains Between Expectations and Reality, PhD Dissertation, Albert-Ludwigs-Universität, Freiburg.

15. Shyshkova, N. (2018), Prospects for the Implementation of Blockchain in Accounting, Accounting and Finance, No. 2, pp. 61-68.

16. Stiller, H., Maille, B., Delaleuf, L., Torri, L., May, D., Dufour, D., Duperrin, B., Henry, J., Paillaré, J., Chesne-Seck, M.-L. (2011), Ruptures et mutations, Documentaliste-Sciences de l'Information, Vol. 48, pp. 36-48.

17. Thivagar, M.L., Hamad, A.A. (2019), Topological Geometry Analysis for Complex Dynamic Systems Based on Adaptive Control Method, Periodicals of Engineering and Natural Sciences, Vol. 7, No. 3, pp. 1345-1353.

18. Wang, Y., Kogan, A. (2017), Designing Privacy-Preserving Blockchain-Based Accounting Information Systems, https://papers.ssrn.com/sol3/papers.cfm?abstract_id=2978281.

19. Wang, Y., Kogan, A. (2018), Designing Confidentiality-Preserving Blockchain-Based Transaction Processing Systems, International Journal of Accounting Information Systems, Vol. 30, pp. 1-18.

20. Ye, Y., Talburt, J. (2019), The Effect of Transitive Closure on the Calibration of Logistic Regression for Entity Resolution, Journal of Information Technology Management, Vol. 10, No. 4, pp. 1-11.

21. CPA Canada (2016), Technological Disruption of Capital Markets and Reporting? An Introduction to Blockchain.

22. Deloitte (2016a), Blockchain: Democratized Trust. Distributed Ledgers and the Future of Value, Deloitte University Press.

23. Deloitte (2016b), Blockchain Technology. A Game-Changer In Accounting?, https://www2.deloitte.com/ content/dam/Deloitte/de/Documents/Innovation/Blockchain_A\%20game-changer\%20in\%20accounting.pdf.

24. ICAEW (2017), Blockchain and the Future of Accountancy, Information Technology Faculty, London.

25. KPMG (2017), Blockchain Accelerates Insurance Transformation, https://assets.kpmg/content/dam/kpmg/ xx/pdf/2017/01/blockchain-accelerates-insurance-transformation-fs.pdf.

26. PwC (2016), What's Next for Blockchain in 2016?, https://www.pwc.lu/en/fintech/docs/pwc-fintech-qawhats-next-for-blockchain-2016.pdf.

27. www.ceccar.ro

28. https://bankunderground.co.uk/2019/05/16/building-blocks-the-useful-elements-of-blockchain/

29. https://seydinabayendanediouf.medium.com/blockchain-a-technical-introduction-part-2-6f75e2a49b89

30. https://www.banque-france.fr/sites/default/files/medias/documents/words-in_the-news_blockchain.pdf

31. https://www.hyperledger.org/news/announcements

t) Acknowledgment: This paper received financial support through the project entitled "DECIDE-Development Through Entrepreneurial Education and Innovative Doctoral and Postdoctoral Research", code POCU/380/6/13/125031, project co-financed from the European Social Fund through the Operational Program Human Capital 2014-2020. 